\title{
Baseline Sensitivity and Resistance-Risk Assessment of Phytophthora capsici to Iprovalicarb
}

\author{
Xiao Hong Lu, Shu Sheng Zhu, Yang Bi, Xi Li Liu, and Jianjun J. Hao
}

First, second, third, and fourth authors: Department of Plant Pathology, China Agricultural University, Beijing 100193; and fifth author: Department of Plant Pathology, Michigan State University, East Lansing 48824.

Accepted for publication 9 June 2010.

\section{ABSTRACT}

Lu, X. H., Zhu, S. S., Bi, Y., Liu, X. L., and Hao, J. J. 2010. Baseline sensitivity and resistance-risk assessment of Phytophthora capsici to iprovalicarb. Phytopathology 100:1162-1168.

Iprovalicarb has been used to control Phytophthora capsici, a devastating pathogen of many economically important crops. To evaluate the risk of fungicide resistance, 158 isolates of $P$. capsici were examined for sensitivity to iprovalicarb by measuring mycelial growth. Values of effective concentrations for $50 \%$ mycelial growth inhibition varied from 0.2042 to $0.5540 \mu \mathrm{g} / \mathrm{ml}$ and averaged $0.3923( \pm 0.0552) \mu \mathrm{g} / \mathrm{ml}$, with a unimodal distribution. This is the first report of $P$. capsici isolates highly resistant to iprovalicarb (resistance factor >100). Resistance of the isolates was stable through 10 transfers on iprovalicarb-free medium, and most resistant isolates had the same level of fitness (mycelial growth, zoospore production, and virulence) as their corresponding parents, indicating that iprovalicarb resistance was independent from other general growth characters. There was cross-resistance among all tested carboxylic acid amide (CAA) fungicides, including iprovalicarb, flumorph, dimethomorph, and mandipropamid, but not with non-CAA fungicides, including azoxystrobin, chlorothalonil, cymoxanil, etridiazole, metalaxyl, and zoxamide. Based on the present results, resistance risk of $P$. capsici to CAAs could be moderate and resistance management should be considered.
Phytophthora capsici Leonian is a widespread and highly damaging plant pathogen. It infects $>50$ species in the families of Cucubitaceae, Solanaceae, and Leguminosae (17,22), causing significant economic losses $(1,17,22,25,27)$. To manage $P$. capsici, methods such as crop rotation, cultural practices, and genetic resistance have been used but chemical control is more effective $(17,25)$. However, there is a limited number of fungicides available, and fungicide resistance is a major challenge. For example, frequent use of metalaxyl or mefenoxam has quickly built up a fungicide-resistant population of $P$. capsici $(22,25,27,32)$, which has significantly reduced the efficacy of the fungicide.

Iprovalicarb is a protective, curative, and eradicative systematic fungicide, and has been used on grape, potato, tomato, tobacco, and many other vegetables (10). It has high biological activity with particular efficacy against oomycete plant pathogens, such as Plasmopara viticola, Bremia lactucae, and Phytophthora spp., except Pythium spp. (10). It is classified into the group carboxylic acid amide (CAA) fungicides, which also includes dimethomorph, flumorph, benthiavalicarb, valifenalate, and mandipropamid (information available on the Fungicide Resistance Action Committee [FRAC] website: http://www.frac.info/frac/index.htm). These fungicides share similar chemical toxophores (13) and antifungal activities $(7,10,29,36)$. Cross-resistance exists amongst all members for the vast majority of the tested isolates of $P$. viticola (15).

The number of CAA fungicides is growing as more fungicides have been released $(13,36)$ and CAAs are replacing phenylamide fungicides as the predominant products for controlling oomycete pathogens. However, CAA resistance could be a serious problem because of the cross-resistance mentioned above. Resistance to CAA fungicides has been monitored in several important patho-

Corresponding authors: X. L. Liu; E-mail address: seedling@cau.edu.cn and J. J. Hao; E-mail address: jjhao@msu.edu

doi:10.1094/PHYTO-12-09-0351

(C) 2010 The American Phytopathological Society gens in the past 20 years, since dimethomorph was introduced. Dimethomorph-resistant isolates of $P$. viticola were first detected in France in 1994 and, subsequently, in more areas of Europe (FRAC website). Flumorph-resistant isolates of Pseudoperonospora cubensis were obtained by UV mutagenesis in the laboratory (40) and after successive application of flumorph in a plastic house (42). No resistance of Phytophthora infestans to CAAs has been found in the field so far (FRAC website), although monitoring for resistance after intensive use of CAAs has been attempted (8). CAA-resistant mutants of $P$. infestans were obtained with UV irradiation and chemical mutagens but growth rates and virulence were reduced significantly $(30,33,39,43)$. Resistance of Peronophythora litchii (36) and Phytophthora capsici to CAAs has not been found in the field (FRAC website) $(22,26)$. The isolates of Peronophythora litchii resistant to dimethomorph (35) and Phytophthora capsici resistant to flumorph or dimethomorph $(18,37$, 38) were obtained artificially and had low fitness and low resistance factors (RFs) (a ratio of the effective concentrations for $50 \%$ mycelial growth inhibition $\left[\mathrm{EC}_{50}\right]$ for a fungicide-resistant mutant relative to the $\mathrm{EC}_{50}$ for the parental isolate). However, recent studies showed that mutants of $P$. capsici resistant to flumorph and dimethomorph that were obtained by using UV treatment $(9,28)$ or repeated exposure to dimethomorph in vitro (34) did not lose their fitness or resistance stability.

Although iprovalicarb has been on the market for $>10$ years, there is not adequate information on the baseline sensitivity and risk assessment of fungicide resistance in any economically important pathogens. The objectives of this study were to (i) determine the baseline sensitivity of $P$. capsici to iprovalicarb, (ii) select resistant isolates, (iii) measure fitness components of the resistant isolates in vitro, and (iv) assay cross-resistance relationship between iprovalicarb and other fungicides on oomycetes.

\section{MATERIALS AND METHODS}

Pathogen isolates and culture conditions. Stems and leaves of pepper (Capsicum annuum Longum) with typical signs and 
symptoms of infection by $P$. capsici were collected in 2007 and 2008 from six provinces of China (Anhui, Beijing, Fujian, Hebei, Inner Mongolia, and Shaanxi), where CAA fungicides had never been used. Small pieces of tissue ( 5 by $3 \mathrm{~mm}$ ) were cut from the margin of lesions on stems or leaves. The tissue was surface disinfested in $70 \%$ ethanol for $3 \mathrm{~min}$ and rinsed three times with sterile water. Tissue pieces were placed onto potato dextrose agar (PDA) (200 g of potato boiled, $18 \mathrm{~g}$ of glucose, $14 \mathrm{~g}$ of agar, and distilled water brought up to 1 liter) plates, amended with carbendazim at $50 \mu \mathrm{g} / \mathrm{ml}$, ampicillin at $100 \mu \mathrm{g} / \mathrm{ml}$, and rifampicin at $50 \mu \mathrm{g} / \mathrm{ml}$. Mycelial plugs were cut $5 \mathrm{~mm}$ in diameter with a cork borer throughout the experiment, unless otherwise described. For mycelial growth measurement, two diameters of the culture were measured perpendicularly and the average of the two measurements was used to calculate the mycelial growth rate. Single-zoospore isolates were obtained using the method described by Lamour and Hausbeck (25), with slight modifications. Briefly, agar plugs from a 3-day-old culture of $P$. capsici on PDA were transferred to carrot agar (CA) (4) plates and incubated for $\approx 4$ days in the dark at $25^{\circ} \mathrm{C}$. After a colony developed to $\geq 8 \mathrm{~cm}$ in diameter, the plates were placed under florescent light $(1,200 \mathrm{~mm}$ per $40 \mathrm{~W}$ ) at 23 to $25^{\circ} \mathrm{C}$ for 5 to 7 days to stimulate ample sporangia production. Plates were flooded with sterile distilled water and incubated at $4^{\circ} \mathrm{C}$ for $30 \mathrm{~min}$, and then at $25^{\circ} \mathrm{C}$ for $30 \mathrm{~min}$. Zoospore suspensions from each culture were spread onto $1.5 \%(\mathrm{wt} / \mathrm{vol})$ water agar and incubated for $16 \mathrm{~h}$ at $25^{\circ} \mathrm{C}$ in the dark. Germinated zoospores were collected microscopically and transferred to PDA plates. Stock cultures of all isolates were maintained on PDA slants at room temperature. All single zoospores were obtained using the same procedure. Isolates PCAS1 (P1314, mating type A1) and PCAS2 (P1319, mating type A2) were single-zoospore isolates (3) and kindly provided by Dr. Michael D. Coffey from the University of California, Riverside.

Fungicides. Technical-grade fungicides included four CAA and six non-CAA fungicides. CAAs included iprovalicarb, dimethomorph, mandipropamid, and flumorph. Non-CAAs included metalaxyl, zoxamide, azoxystrobin, cymoxanil, chlorothalonil, and etridiazole. All of these fungicides were dissolved in acetone, except mandipropamid, which was suspended in methanol, to prepare stock solutions $\left(1 \times 10^{4} \mu \mathrm{g} / \mathrm{ml}\right)$ and stored at $4^{\circ} \mathrm{C}$ in the dark to preserve fungicide activity. The stock solutions were added to molten PDA at various rates (Table 1) after the medium was cooled to $\approx 50^{\circ} \mathrm{C}$. All concentrations are represented in units of active ingredient.

Baseline sensitivity of $\boldsymbol{P}$. capsici to iprovalicarb. The sensitivity of 158 isolates of $P$. capsici to iprovalicarb was determined by measuring mycelial growth on agar plates. Isolates were incubated on PDA at $25^{\circ} \mathrm{C}$ for 4 days in the dark. Agar plugs were cut from these cultures and placed mycelia-side down on PDA amended with iprovalicarb at a series of concentrations (Table 1). The final acetone concentrations in the medium were all adjusted to $0.1 \%$. After 3 days of growth at $25^{\circ} \mathrm{C}$ in the dark, colony diameters (minus the diameter of the inoculation plug) were measured. There were four replicates for each treatment.

Generation of iprovalicarb-resistant isolates. Mass selection from zoospores. Two isolates of P. capsici (PCAS1 and PCAS2) were used to select for iprovalicarb-resistant isolates. Concentrations of zoospore suspensions of PCAS1 and PCAS2 were adjusted via dilution to $\approx 2.0 \times 10^{7}$ zoospores $/ \mathrm{ml}$ with the aid of a hemacytometer. Resistance was screened by inoculating zoospores onto PDA plates amended with iprovalicarb at $5 \mu \mathrm{g} / \mathrm{ml}$ (PDI), at which concentration cystospores of sensitive $P$. capsici isolates were completely inhibited from germinating. Plates without fungicides were used as a control. After incubating for 5 to 7 days at $25^{\circ} \mathrm{C}$ in the dark, putative resistance of the culture grown on PDI plates was confirmed by transferring the colonies to a new PDI plate. This transfer was repeated and then singlezoospore isolates were generated before testing for iprovalicarb sensitivity. After 3 days of incubation at $25^{\circ} \mathrm{C}$ in the dark on PDA amended with various concentrations of iprovalicarb, colony diameters (minus the diameter of the inoculation plug) were measured.

Selection from oospores. In all, 38 sexual progeny (oospores) were obtained previously in our laboratory from self crossings of PCAS1 (A1 mating type) (28). This was done following the method by Ko (23). Briefly, two isolates with opposite mating types were paired on $\mathrm{CA}$ media and separated by a sterile polycarbonate membrane (47 $\mathrm{mm}$ in diameter; Whatman Inc., Piscataway, NJ). The membrane allows exchange of hormones required for sexual reproduction but blocks mycelia from penetration. After 3 days of incubation on fungicide-free PDA medium, these strains were transferred onto PDI. Isolates that grew on PDI were examined for fungicide resistance as described above.

Characterization of iprovalicarb-resistant isolates. Resistance stability. The stability of resistant phenotypes was assessed by 10 successive transfers of all mutants on fungicide-free PDA plates. Sensitivity to iprovalicarb was determined by the percentage of growth inhibition on PDI $(50 \mu \mathrm{g} / \mathrm{ml})$ after the first and the tenth subculture. A factor of sensitivity change (FSC) was calculated as the percentage of mycelial growth inhibition in the 1st transfer divided by that in the 10th transfer.

In addition, two asexual and two sexual progeny were randomly selected for resistance stability through five successive transfers with zoospores. A zoospore suspension produced at each transfer as described above was used to reinoculate new CA plates. At least 50 single-zoospore isolates randomly sampled from each isolate were examined for iprovalicarb sensitivity on PDI.

Effect of temperature on mycelial growth. Nine isolates (two sensitive, three asexual resistant, and four sexual resistant isolates selected randomly) were incubated on PDA at 10, 18, 25, 30, and $37^{\circ} \mathrm{C}$, respectively. Two perpendicular diameters of each colony were measured after 5 days of incubation in the dark. For each isolate, there were four replicated plates at each temperature.

Sporulation and cystospore germination in vitro. Sporangia of P. capsici were produced as described above. Sporulation of each

TABLE 1. Concentrations used to determine the sensitivity to fungicides in iprovalicarb-sensitive and -resistant Phytophthora capsici isolates

\begin{tabular}{lll}
\hline & & Concentrations $(\mu \mathrm{g} / \mathrm{ml})$ \\
\cline { 2 - 3 } Fungicides & Iprovalicarb-sensitive isolates & Iprovalicarb-resistant isolates \\
\hline Iprovalicarb & $0,0.3,0.35,0.4,0.45,0.5,0.55$ & $0,50,100,150,200,300$ \\
Flumorph & $0,0.5,0.8,1,1.5,2,3$ & $0,10,15,20,30,40$ \\
Dimethomorph & $0,0.1,0.2,0.4,0.6,0.8$ & $0,0.5,1,2,3,5$ \\
Mandipropamid & $0,0.015,0.02,0.025,0.03,0.035$ & $0,100,200,400,800,1000$ \\
Metalaxyl & $0,0.3,0.6,1,5,10,20,50$ & $0,0.3,0.6,1,5,10,20,50$ \\
Chlorothalonil & $0,2.5,5,10,50,100$ & $0,2.5,5,10,50,100$ \\
Cymoxanil & $0,5,10,20,40,80,160$ & $0,5,10,20,40,80,160$ \\
Etridiazole & $0.5,1,1.5,2,5$ & $0,0.5,1,1.5,2,5$ \\
Zoxamide & $0,0.02,0.04,0.1,0.4,1$ & $0,0.02,0.04,0.1,0.4,1$ \\
Azoxystrobin & $0,20,40,60,80,100$ & $0,20,40,60,80,100$ \\
\hline
\end{tabular}


isolate was assayed as follows. First, 10 plugs $\approx 5 \mathrm{~mm}$ from the culture margin and 10 plugs from the area of the culture near the initial inoculum plug were harvested. Then, all 20 plugs were placed separately in a petri dish with $10 \mathrm{ml}$ of sterile distilled water to allow zoospores release as described above. The number of zoospores per square centimeter from each colony was counted. Cystospore germination was determined after $12 \mathrm{~h}$ of incubation of zoospore suspensions at $25^{\circ} \mathrm{C}$ in the dark. Four drops ( $10 \mu \mathrm{l} / \mathrm{drop})$ of the suspension were counted per isolate and $>100$ cystospores were examined. Percentage of cystospore germination (a germinated cystospore was confirmed if the length of germ tube was more than diameter of the cystospore) was calculated.

Virulence on bell pepper leaves. Virulence is used here as defined by Sacristan and Garcia-Arenal (31): "the degree of damage caused to a host by parasite infection." A mycelial plug of $P$. capsici isolates was inoculated on detached bell pepper (cv. Tedaqiemen) leaf. Fully expanded leaves with the same age and area were excised from greenhouse-grown pepper plants and rinsed three times with sterile distilled water. For each isolate, 12 replicated leaves were placed on a filter paper (Whatman Qualitative Grade Plain Circles and Sheets-Grade 1, diameter $18.5 \mathrm{~cm}$ ) in a $20-\mathrm{cm}$ petri dish, with $15 \mathrm{ml}$ of sterile distilled water per dish to maintain humidity. The inoculated leaves were incubated in a room with a humidifier at $25^{\circ} \mathrm{C}$ with $12 \mathrm{~h}$ of light and $12 \mathrm{~h}$ of darkness. Six days after inoculation, disease was assessed by calculating the percentage of lesion area in the whole leaf.

Cross-resistance. Iprovalicarb-resistant and-sensitive isolates were used to assess their sensitivity to four CAA fungicides, including iprovalicarb, flumorph, dimethomorph, and mandipropamid, as well as non-CAA fungicides, including metalaxyl (phenylamide), chlorothalonil (chloronitrile), cymoxanil (cyanoacetamideoxime), etridiazole (thiadiazole), zoxamide (benzamide), and azoxystrobin (quinone outside inhibitor). This was done by using the same method of mycelial growth inhibition described above at various final concentrations (Table 1). $\mathrm{EC}_{50}$ values for all isolates to these fungicides were calculated respectively.

Statistical analysis. All data was analyzed using SAS software (version 9; SAS Inc., Cary, $\mathrm{NC}$ ). The $\mathrm{EC}_{50}$ value for each isolate was calculated by regression analysis using the percentage of growth inhibition against the logarithmic value of fungicide concentration. The procedure GLM was used for variance analysis, and Fisher's least significant difference (LSD) multiple range test was performed for separating means. Procedure

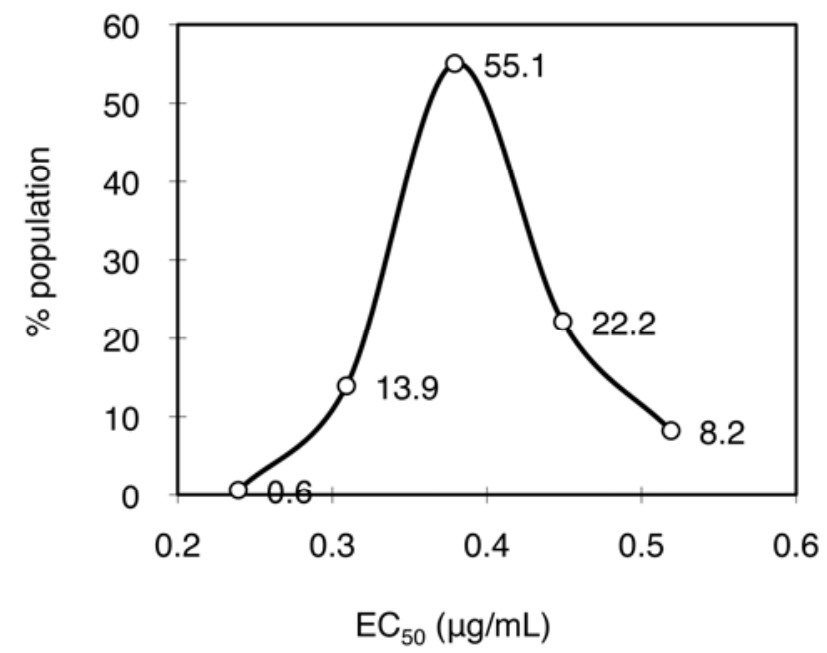

Fig. 1. Frequency distribution of the effective concentration for $50 \%\left(\mathrm{EC}_{50}\right)$ of mycelial growth inhibition of iprovalicarb for 158 isolates of Phytophthora capsici, which were collected from areas never exposed to carboxylic acid amide fungicides. Values on the curve show frequencies of isolates with corresponding $\mathrm{EC}_{50}$.
Spearman rank correlation was used to analyze cross-resistance. $\mathrm{EC}_{50}$ values were transformed to logarithmic values $\left(\log \mathrm{EC}_{50}\right)$ before running the analysis of cross-resistance.

\section{RESULTS}

Baseline sensitivity to iprovalicarb. The iprovalicarb sensitivity of the $158 \mathrm{P}$. capsici isolates varied and their $\mathrm{EC}_{50}$ values were 0.2042 to $0.5540 \mu \mathrm{g} / \mathrm{ml}$, with a mean of $0.3923( \pm 0.0552)$ $\mu \mathrm{g} / \mathrm{ml}$. The ratio of the highest to the lowest $\mathrm{EC}_{50}$ values was 2.71 . The distribution of $\mathrm{EC}_{50}$ values was unimodal and positively skewed (Fig. 1). Therefore, no resistance was observed in field isolates. There was no correlation between isolate sensitivity and geographic location, because all areas had both low and high $\mathrm{EC}_{50}$ isolates (Table 2).

Generation of iprovalicarb-resistant isolates. Six iprovalicarb-resistant isolates were obtained spontaneously from zoospores of parent strain PCAS2 at a low frequency $\left(6.0 \times 10^{-12}\right.$, calculated as the ratio of the number of resistant isolates obtained over total number of zoospores tested times rate of zoospore germination). All RFs for iprovalicarb of the six resistant isolates were $>340$ (Table 3). No resistant isolates were obtained from zoospores of parent strain PCAS1. However, among the 38 sexual progeny of PCAS1, 9 showed resistance; therefore, the frequency was 0.24 . These nine isolates were highly resistant to iprovalicarb, with all RFs $>250$. No sexual progeny was obtained from PCAS2 because of failure of oospore germination.

Characterization of iprovalicarb-resistant isolates. Resistance stability. Iprovalicarb-resistant isolates had a varied resistance after 10 transfers, showing stable (Table 3, R2-5), increased (Table 3, R2-6), and decreased resistance (Table 3, R1-7). However, none of them was inhibited by $>50 \%$ at the 10 th transfer; thus, $\mathrm{EC}_{50}$ values for all isolates were $>50 \mu \mathrm{g} / \mathrm{ml}$ and all RFs $>100$. For the zoospore stability test, $>50$ single-zoospore progeny of the selected resistant isolates (R1-3, R1-7, R2-2, and R2-4) grew well on iprovalicarb-amended PDA medium after five asexual generations.

Effect of temperature on mycelial growth. For all the tested isolates of $P$. capsici, $25^{\circ} \mathrm{C}$ was the optimal temperature for mycelial growth because growth decreased at temperatures $<25^{\circ} \mathrm{C}$ or $>25^{\circ} \mathrm{C}$ (Fig. 2). For PCAS1 and its resistant progeny (Fig. 2A), all four isolates grew slower than PCAS1 at $10^{\circ} \mathrm{C}$. All four isolates grew either faster than or at a similar rate to PCAS1 at 18, 25,30 , and $37^{\circ} \mathrm{C}$, with exceptions for R1-7 at $18^{\circ} \mathrm{C}$ and $\mathrm{R} 1-6$ at $37^{\circ} \mathrm{C}$. This showed a pattern that mycelial growth of progeny from PCAS1 that was reduced at $10^{\circ} \mathrm{C}$ but enhanced at a temperature $>25^{\circ} \mathrm{C}$. For PCAS2 and its resistant progeny (Fig. 2B), all three isolates grew faster than PCAS2 at 10 and $18^{\circ} \mathrm{C}$ but slower at higher temperatures $\left(25,30\right.$, and $\left.37^{\circ} \mathrm{C}\right)$, with the ex-

TABLE 2. Range of resistance levels to iprovalicarb of Phytophthora capsici isolates from different locations in China

\begin{tabular}{lccc}
\hline & & \multicolumn{2}{c}{$\mathrm{EC}_{50}(\mu \mathrm{g} / \mathrm{ml})^{\mathrm{z}}$} \\
\cline { 3 - 4 } Location $^{\mathrm{x}}$ & No. $^{\mathrm{y}}$ & $\mathrm{Range}$ & Mean \\
\hline Fuyang, Anhui & 15 & $0.2042-0.4627$ & $0.3859 \mathrm{c}$ \\
Pinggu, Beijing & 15 & $0.3140-0.5090$ & $0.3858 \mathrm{c}$ \\
Shunyi, Beijing & 13 & $0.3540-0.5540$ & $0.4191 \mathrm{~b}$ \\
Dingxing, Hebei & 29 & $0.3220-0.4725$ & $0.3925 \mathrm{bc}$ \\
Dingzhou, Hebei & 25 & $0.3018-0.3906$ & $0.3531 \mathrm{~d}$ \\
Fuzhou, Fujian & 12 & $0.3524-0.4724$ & $0.3858 \mathrm{c}$ \\
Bayanzhuoer, Inner Mongolia & 25 & $0.3142-0.4385$ & $0.3633 \mathrm{~cd}$ \\
Yangling, Shaanxi & 24 & $0.3770-0.5070$ & $0.4597 \mathrm{a}$ \\
\hline
\end{tabular}

${ }^{\mathrm{x}}$ Location of sampling (city, province).

y Number of isolates.

${ }^{\mathrm{z}} \mathrm{EC}_{50}=$ effective concentration for $50 \%$ of mycelial growth inhibition. Multiple range test was used to compare mean $\mathrm{EC}_{50}$ values using Fisher's least significant difference. Values followed by same letters are not significantly different at $P=0.05$. 
ception of R2-2 at $37^{\circ} \mathrm{C}$. The growth pattern for this group of $P$. capsici isolates was that mycelial growth of resistant progeny was enhanced at temperatures 10 and $18^{\circ} \mathrm{C}$ but decreased at temperatures $>25^{\circ} \mathrm{C}$.

Sporulation, cystospore germination, and virulence in vitro. Spore production and cystospore germination of PCAS1 were significantly higher $(P<0.05)$ than those of its resistant progeny but there was no significant difference in both spore production and cystospore germination between PCAS2 and its resistant progeny (Table 4). Both iprovalicarb-sensitive and -resistant isolates were virulent, causing typical and severe symptoms on detached bell pepper leaves. Only one resistant isolate (R1-1) produced a significantly larger lesion $(P<0.05)$ than its parent isolate PCAS1; all other isolates caused lesion areas similar to their parental isolates (Table 4).

Cross-resistance. There was a highly correlated positive relationship among all the four CAAs tested. For example, $\log \mathrm{EC}_{50}$ of iprovalicarb was positively correlated with $\log \mathrm{EC}_{50}$ of flumorph, dimethomorph, and mandipropamid for $P$. capsici isolates. The values of Spearman's rho $(\rho)$ were all $>0.80(P<$
TABLE 4. Fitness components of iprovalicarb-resistant and -sensitive isolates of Phytophthora capsici ${ }^{\mathrm{Z}}$

\begin{tabular}{lcccc}
\hline Isolate & $\begin{array}{c}\text { Mycelial } \\
\text { growth } \\
(\mathrm{mm})\end{array}$ & $\begin{array}{c}\text { Sporulation } \\
\left(\times 10^{5}\right. \\
\left.\text { spores } / \mathrm{cm}^{2}\right)\end{array}$ & $\begin{array}{c}\text { Cystospore } \\
\text { germination } \\
(\%)\end{array}$ & $\begin{array}{c}\text { Lesion area } \\
\text { on pepper } \\
\text { leaves }(\%)\end{array}$ \\
\hline Sexual progeny & & & & \\
PCAS1 & $60.8 \mathrm{c}$ & $2.33 \mathrm{a}$ & $57.74 \mathrm{a}$ & $80.57 \mathrm{~b}$ \\
R1-1 & $63.0 \mathrm{~b}$ & $0.35 \mathrm{~b}$ & $25.93 \mathrm{~b}$ & $91.43 \mathrm{a}$ \\
R1-3 & $67.0 \mathrm{a}$ & $0.57 \mathrm{~b}$ & $27.26 \mathrm{~b}$ & $80.36 \mathrm{~b}$ \\
R1-6 & $68.3 \mathrm{a}$ & $0.99 \mathrm{~b}$ & $24.87 \mathrm{~b}$ & $82.86 \mathrm{ab}$ \\
R1-7 & $68.7 \mathrm{a}$ & $0.71 \mathrm{~b}$ & $32.12 \mathrm{~b}$ & $78.21 \mathrm{~b}$ \\
Asexual progeny & & & & \\
PCAS2 & $60.5 \mathrm{a}$ & $2.48 \mathrm{a}$ & 37.43 & 86.43 \\
R2-2 & $57.2 \mathrm{~b}$ & $2.40 \mathrm{a}$ & 36.27 & 83.93 \\
R2-3 & $57.5 \mathrm{~b}$ & $2.62 \mathrm{a}$ & 42.18 & 90.00 \\
R2-4 & $53.5 \mathrm{c}$ & $4.31 \mathrm{a}$ & 44.80 & 92.50 \\
\hline
\end{tabular}

${ }^{\mathrm{z}}$ Isolates designed as R1-X are progeny of PCAS1 produced by selfing, and isolates designed as $\mathrm{R} 2-\mathrm{X}$ are progeny of PCAS2 produced by mass selection on iprovalicarb-amended medium. Multiple comparisons were conducted for each column in the table, for sexual and asexual progeny, respectively, using Fisher's least significant difference. Values followed by the same letter indicate no significant difference at level of $P=0.05$.

TABLE 3. Resistance factor and stability for iprovalicarb resistant isolates of Phytophthora capsici

\begin{tabular}{|c|c|c|c|c|c|}
\hline Isolate $^{v}$ & $\mathrm{EC}_{50}(\mu \mathrm{g} / \mathrm{ml})^{\mathrm{w}}$ & $\mathrm{RF}^{\mathrm{x}}$ & $1 \mathrm{st}(\%)^{\mathrm{y}}$ & 10 th $(\%)^{\mathrm{y}}$ & $\mathrm{FSC}^{\mathrm{z}}$ \\
\hline \multicolumn{6}{|c|}{ Sexual progeny } \\
\hline PCAS1 & 0.59 & $\ldots$ & 100.00 & 100.00 & 1.00 \\
\hline R1-1 & 430.54 & 726 & 7.25 & 20.90 & 2.88 \\
\hline $\mathrm{R} 1-2$ & 653.57 & 1,108 & 10.53 & 20.63 & 1.96 \\
\hline $\mathrm{R} 1-3$ & 261.61 & 443 & 12.25 & 24.24 & 1.98 \\
\hline $\mathrm{R} 1-4$ & 361.37 & 612 & 25.68 & 37.68 & 1.47 \\
\hline $\mathrm{R} 1-5$ & 282.7 & 479 & 21.62 & 41.79 & 1.93 \\
\hline R1-6 & 152.19 & 257 & 18.57 & 27.69 & 1.49 \\
\hline $\mathrm{R} 1-7$ & 185.58 & 313 & 8.70 & 32.86 & 3.78 \\
\hline $\mathrm{R} 1-8$ & 265.12 & 447 & 14.47 & 24.66 & 1.70 \\
\hline R1-9 & 243.21 & 410 & 4.83 & 10.12 & 2.10 \\
\hline \multicolumn{6}{|c|}{ Asexual progeny } \\
\hline PCAS2 & 0.36 & $\ldots$ & 100.00 & 100.00 & 1.00 \\
\hline R2-1 & 153.78 & 428 & 18.42 & 27.69 & 1.50 \\
\hline R2-2 & 156.37 & 433 & 18.06 & 33.33 & 1.85 \\
\hline $\mathrm{R} 2-3$ & 173.88 & 483 & 17.39 & 30.77 & 1.77 \\
\hline $\mathrm{R} 2-4$ & 125.01 & 347 & 24.68 & 27.94 & 1.13 \\
\hline $\mathrm{R} 2-5$ & 137.37 & 381 & 26.51 & 25.00 & 0.94 \\
\hline R2-6 & 126.08 & 350 & 23.68 & 19.35 & 0.82 \\
\hline
\end{tabular}

${ }^{v}$ PCAS1 and PCAS2 are wild-type isolates. Isolates designed R1-X are progeny of PCAS1 produced by sexual recombination, and isolates designed R2-X are progeny of PCAS2 produced by repeated selection on iprovalicarb-amended medium.

${ }^{\mathrm{w}} \mathrm{EC}_{50}=$ effective concentration for $50 \%$ of mycelial growth inhibition.

${ }^{\mathrm{x}} \mathrm{RF}=$ resistance factor, a ratio of $\mathrm{EC}_{50}$ for a fungicide-resistant mutant relative to the $\mathrm{EC}_{50}$ for the parental isolate.

${ }^{y}$ Inhibition values (1st and 10th) were determined on agar plates amended with iprovalicarb at $50 \mu \mathrm{g} / \mathrm{ml}$.

${ }^{z} \mathrm{FSC}=$ factor of sensitivity change, the ratio of inhibition values at the 1 st transfer over the 10th transfer.
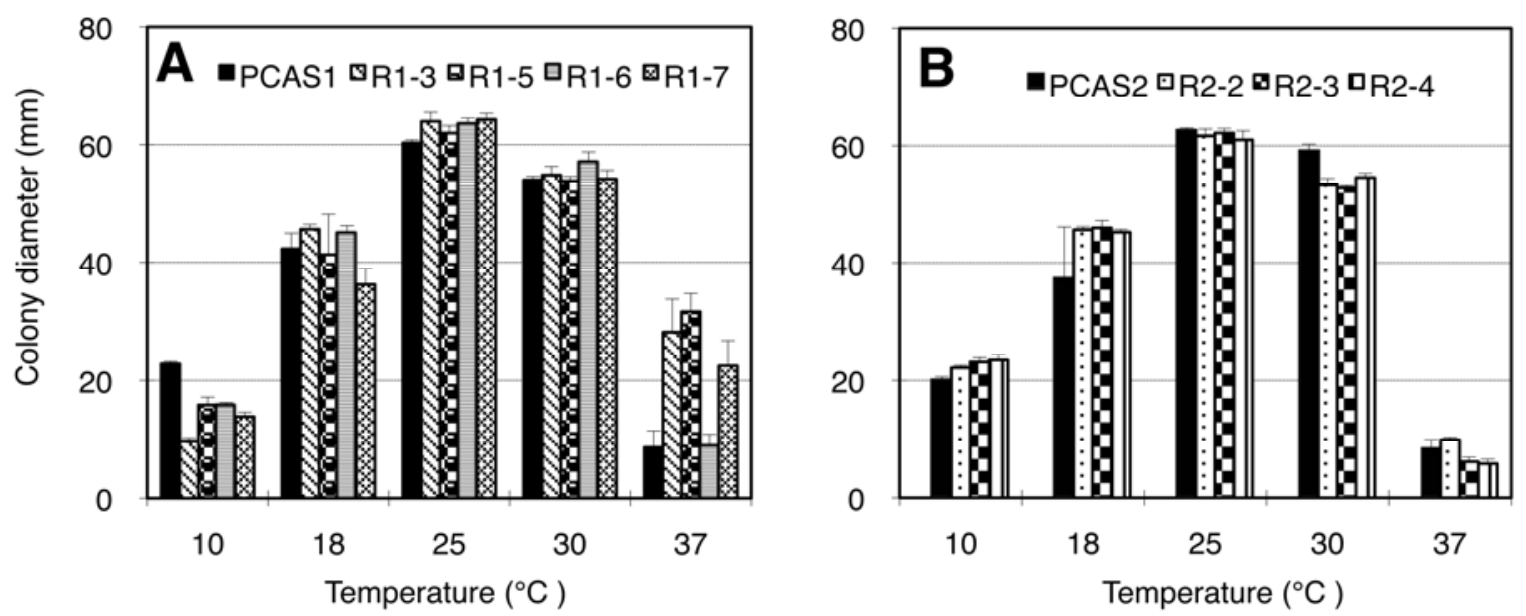

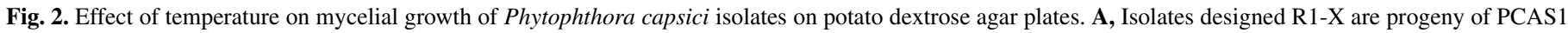

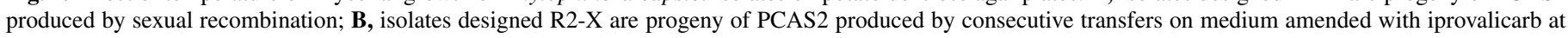
$5 \mu \mathrm{g} / \mathrm{ml}$. Caped bars on the top of columns indicate standard errors. Mycelial growth was measured on the fifth day of incubation. 
0.0001) (Fig. 3A to C). These isolates with high iprovalicarb RFs also had high mandipropamid RFs but low flumorph and dimethomorph RFs. No cross-resistance was detected between iprovalicarb and most of the non-CAA fungicides, such as metalaxyl, zoxamide, azoxystrobin, etridiazole, and chlorothalonil $(P>0.05)$. However, there was a negative correlation between iprovalicarb and cymoxanil $(\rho=-0.70, P<0.0001)$. Negative correlation also existed between cymoxanil and dimethomorph (Fig. 3E) and between cymoxanil and flumorph (Fig. 3F).

\section{DISCUSSION}

Our results showed that $P$. capsici is sensitive to iprovalicarb in nature. The ratio of the highest to lowest $\mathrm{EC}_{50}$ values was only
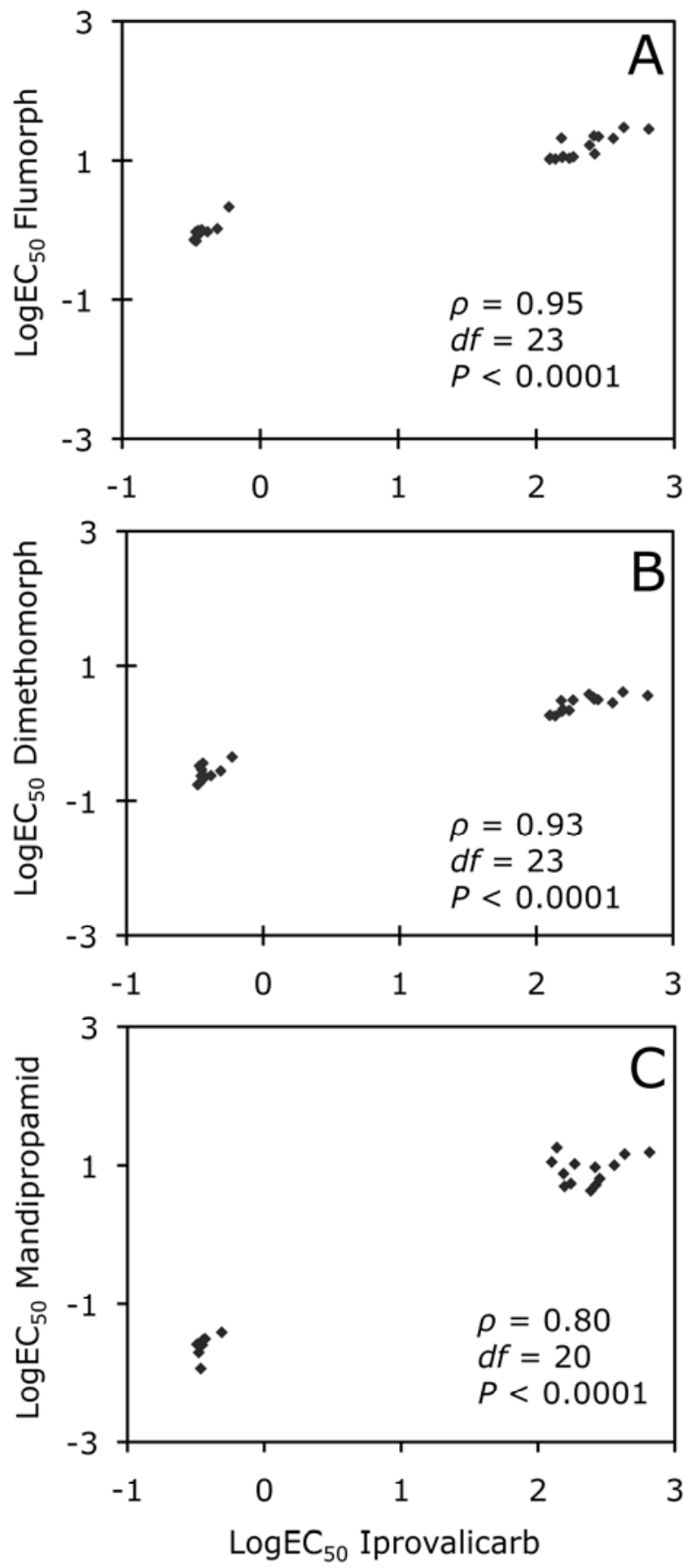

2.71 , indicating a low variation in sensitivity among isolates. The data for iprovalicarb sensitivity will provide a baseline for monitoring sensitivity changes in $P$. capsici populations to CAA fungicides. $\mathrm{EC}_{50}$ in this study was determined by measuring mycelial growth because of the easiness; however, cystospore germination might be the stage at which Phytophthora spp. are most sensitive to CAAs (6).

Although a CAA fungicide-resistant mutation for $P$. capsici has never been reported in nature, our laboratory data has demonstrated that resistance could be detected from both sexual (PCAS1) and asexual (PCAS2) progenies with different resistance frequencies. One of the reasons for two different resistance frequencies might be that resistance is inherited in a recessive manner, because Gisi et al. reported that resistance to CAAs in
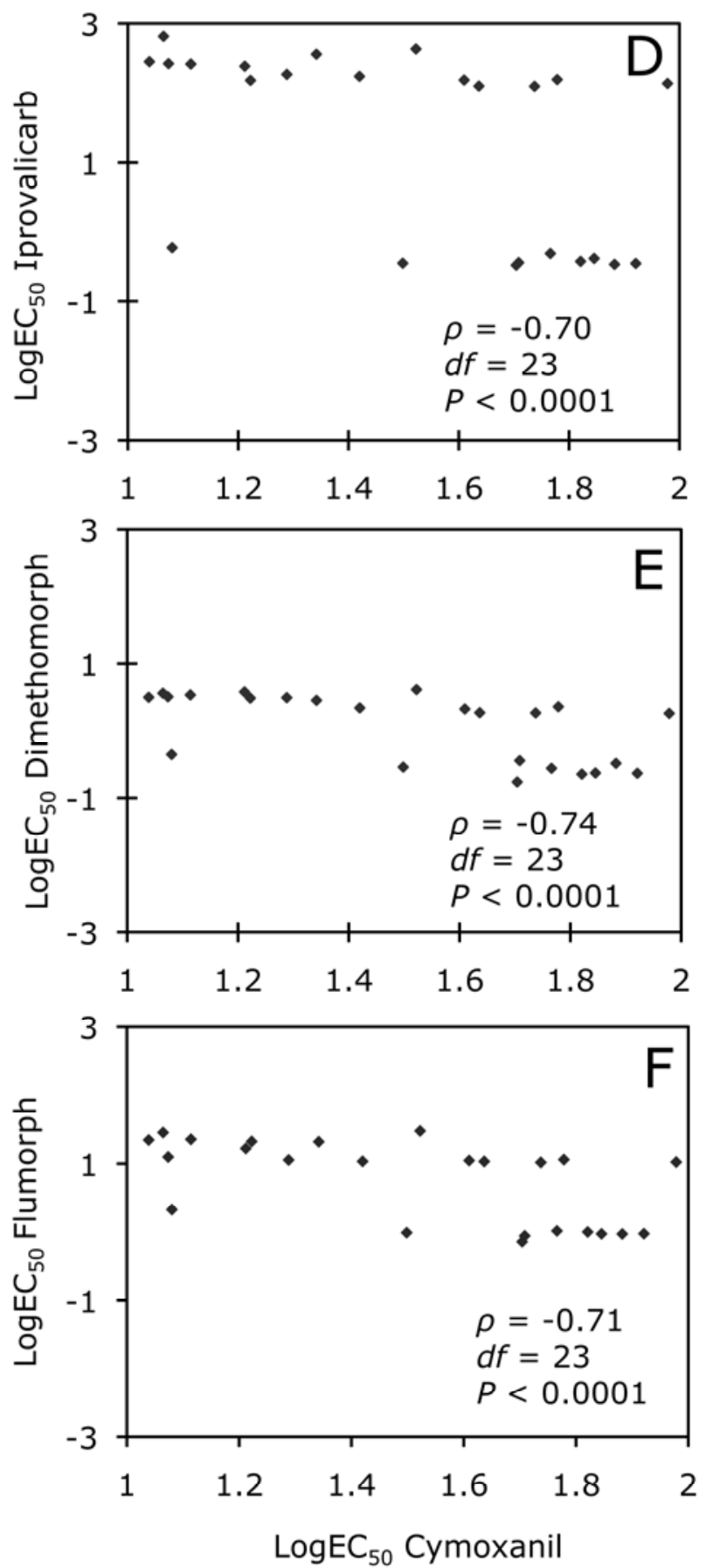

Fig. 3. Rank correlation analysis for cross resistance among different fungicides. Data shown in logarithmic values of effective concentrations for $50 \%$ mycelial growth inhibition $\left(\log \mathrm{EC}_{50}\right)$ among Phytophthora capsici isolates for fungicide combinations: A, iprovalicarb and flumorph; $\mathbf{B}$, iprovalicarb and dimethomorph; $\mathbf{C}$, iprovalicarb and mandipropamid; D, cymoxanil and iprovalicarb; E, cymoxanil and dimethomorph; and F, cymoxanil and flumorph. 
Plasmopara viticola is controlled by two recessive genes (15). This means that a resistant phenotype can only be observed when an individual isolate of this diploid oomycete is homozygous resistant. Our results suggest that PCAS1 is heterozygote. According to the low resistance frequency of mutation, PCAS2 might be homozygote but further evidence is needed to prove it.

Sexual reproduction could increase the resistance risk by gene recombination, which creates more opportunities for recessive genes to be expressed in a homozygous isolate. This may explain why the risk of CAAs resistance is different among Phytophthora infestans, Plasmopara viticola, and Pseudoperonospora cubensis. Plasmopara viticola was found to complete its sexual cycle in Europe (21) and had built up a CAA-resistant population in a short time (FRAC website). For Phytophthora infestans, there is little evidence for sexual reproduction in most parts of the world (11). Therefore, as suggested by Rubin et al. (30), CAA-resistant isolates of $P$. infestans have not been found in nature. The resistance risk for flumorph in Pseudoperonospora cubensis was higher in vivo than in vitro, probably because of the lack of sexual reproduction in the laboratory condition $(40,42)$. The fact that Phytophthora capsici is heterothallic and that the ratio of two mating types is almost $1: 1$ in the field $(17,25)$ indicates that the possibility of sexual reproduction is high, which could potentially lead to the development of CAA resistance by DNA recombination.

To our knowledge, this is the first report that isolates of $P$. capsici highly resistant to CAA fungicides can be produced spontaneously. We showed that all of these isolates of $P$. capsici were highly resistant to iprovalicarb, with RFs $>100$, and stably inherited the resistance via asexual progeny, including hyphae and zoospores. Resistant isolates of $P$. capsici, obtained both spontaneously and by self-crossing, indicated that iprovalicarb resistance is independent from growth characteristics. In contrast, CAA resistance of $P$. infestans, identified only in the laboratory, could be associated with fitness penalties (30).

In our study, progeny of wild types were either highly sensitive or highly resistant to CAAs. A $t$ test result indicated that the $\mathrm{EC}_{50}$ values were significantly different between the sensitive and resistant isolates to CAAs; therefore, we assumed that the resistance of spontaneously obtained isolates was qualitative rather than quantitative. This is in accord with the conclusion of Gisi et al., who studied resistance in Plasmopara viticola to CAAs (15). The most recent report showed that resistance to CAAs in $P$. viticola might be controlled by gene $\operatorname{ces} A 3$, which is involved in cellulose synthesis (12), and the mutation in PiCesA3 caused mandipropamid insensitivity (2). This could be true in our case.

Iprovalicarb-resistant isolates of Phytophthora capsici were also resistant to other CAAs tested. The same conclusion of crossresistance was made for Plasmopara viticola (15), Phytophthora infestans (39), and Pseudoperonospora cubensis (40). Resistance to one fungicide in a pathogen could mean that other fungicides in the same CAA group may fail even before they are applied due to cross-resistance. We found that these high iprovalicarb-resistant isolates showed higher resistance to mandipropamid than to flumorph and dimethomorph. Although there is a similar mode of action for all CAAs, they might bind to somewhat different sites on the same protein, which results in similar specificity but with different levels of resistance. Several mechanisms of modes of action have been suggested, such as disruption of cell wall deposition of the pathogen $(5,14,19,20,24,29)$, inhibition of phospholipids biosynthesis (16), disruption of the F-actin organization and cell polar growth (41), or no disruption of microfilament organization (7). However, recent research showed the cellulose synthase-like PiCesA3 was the protein target of mandipropamid. Interestingly, we found a negative correlation between resistance to cymoxanil and resistance to CAAs. Comparing the cymoxanil sensitivity between CAA-resistant and -susceptible isolates using a $t$ test showed that $\mathrm{EC}_{50}$ values were significantly different between the two classes (data not shown). Obviously, such a relationship can be used in fungicide resistance management but the phenomenon should first be confirmed with further research.

With resistance in Phytophthora capsici resulting mainly from sexual reproduction, a recessive nature of resistance, apparent high pathogenic fitness of resistant isolates, cross-resistance among all CAAs, and lack of long-distance transport of propagules, we conclude that the risk of resistance to iprovalicarb in $P$. capsici could be intermediate, which is higher than for $P$. infestans but lower than for Plasmopara viticola and Pseudoperonospora cubensis. This conclusion may not be in full agreement with others who conducted studies using unstable CAA-resistant mutants $(18,37,38)$. To avoid the rapid development of resistance to CAAs, reducing the number of fungicide applications, applying CAAs in mixture with multisite or noncross-resistant fungicides, and alternating application of CAAs with other fungicides that have a different mode of action should be components of disease management in the field.

\section{ACKNOWLEDGMENTS}

This work was funded by the National Science Foundation of China (grant no. 30671390). We thank M. D. Coffey for kindly providing strains, F. Chen and Z. Gao for collecting isolates from Fuzhou and Fuyang, and L. Hanson for reviewing and providing professional opinions on this manuscript.

\section{LITERATURE CITED}

1. Babadoost, M. 2000. Outbreak of Phytophthora foliar blight and fruit rot in processing pumpkin fields in Illinois. Plant Dis. 84:1345.

2. Blum, M., Boehler, M., Randall, E., Young, V., Csukai, M., Kraus, S., Moulin, F., Scalliet, G., Avrova, A. O., Whisson, S. C., and Fonne-Pfister, R. 2010. Mandipropamid targets the cellulose synthase-like PiCesA3 to inhibit cell wall biosynthesis in the oomycete plant pathogen, Phytophthora infestans. Mol. Plant Pathol. 11:227-243.

3. Bower, L. A., and Coffey, M. D. 1985. Development of laboratory tolerance to phosphorus-acid, fosetyl-al, and metalaxyl in Phytophthora capsici. Can. J. Plant Pathol. Rev. Can. Phytopathol. 7:1-6.

4. Brasier, C. M., and Griffin, M. J. 1979. Taxonomy of Phytophthora palmivora on cocoa. Trans. Br. Mycol. Soc. 72:111-143.

5. Cohen, Y., Balder, A., and Cohen, B. H. 1995. Dimethomorph activity against oomycete fungal plant pathogens. Phytopathology 85:1500-1506.

6. Cohen, Y., and Gisi, U. 2007. Differential activity of carboxylic acid amide Fungicides against various developmental stages of Phytophthora infestans. Phytopathology 97:1274-1283.

7. Cohen, Y., Rubin, A., and Gotlieb, D. 2008. Activity of carboxylic acid amide (CAA) fungicides against Bremia lactucae. Eur. J. Plant Pathol. 122:169-183.

8. Cohen, Y., Rubin, E., Hadad, T., Gotlieb, D., Sierotzki, H., and Gisi, U. 2007. Sensitivity of Phytophthora infestans to mandipropamid and the effect of enforced selection pressure in the field. Plant Pathol. 56:836-842.

9. Cui, X. L., Meng, Q. X., Bi, Y., Wu, P. F., and Liu, X. L. 2009. Baseline sensitivity and laboratory mutants of Phytophthora capsici resistant to dimethomorph. Acta. Phytopathol. Sin. 39:630-637.

10. Dutzmann, S. 1999. Iprovalicarb (SZX 0722) - a novel fungicide with specific activity against oomycetes. Pflanzenschutz Nachr. Bayer (Ger. Ed.) 52:15-32.

11. Fry, W. 2008. Phytophthora infestans: the plant (and $R$ gene) destroyer. Mol. Plant Pathol. 9:385-402.

12. Gisi, U., Blum, M., Moulin, F., Fonne, R., and Sierotzki, H. 2009. Molecular and genetic aspects of CAA mode of action and resistance. (Abstr.) Phytopathology 99:S169.

13. Gisi, U., Lamberth, C., Mehl, A., and Seitz, T. 2007. Carboxylic acid amide (CAA) fungicides. Pages 651-674 in: Modern Crop Protection Compounds. W. Kramer and U. Schirmer, eds. WILEY-VCH.

14. Gisi, U., and Sierotzki, H. 2008. Fungicide modes of action and resistance in downy mildews. Eur. J. Plant Pathol. 122:157-167.

15. Gisi, U., Waldner, M., Kraus, N., Dubuis, P. H., and Sierotzki, H. 2007. Inheritance of resistance to carboxylic acid amide (CAA) fungicides in Plasmopara viticola. Plant Pathol. 56:199-208.

16. Griffiths, R. G., Dancer, J., O’Neill, E., and Harwood, J. L. 2003. A mandelamide pesticide alters lipid metabolism in Phytophthora infestans. New Phytol. 158:345-353. 
17. Hausbeck, M. K., and Lamour, K. H. 2004. Phytophthora capsici on vegetable crops: research progress and management challenges. Plant Dis. 88:1292-1303.

18. Huang, L. H., Liu, J. L., Si, N. G., Zhang, Z. J., and Chen, J. 2004. Studies on Phytophthora capsici resistance to flumorph. Chin. J. Pestic. 43:261-262.

19. Jende, G., Steiner, U., and Dehne, H. W. 1999. Effects of iprovalicarb (SZX 0722) on the dedevelopment of Phytophthora infestans in tomato plants. Pflanzenschutz Nachr. Bayer (Ger. Ed.) 52:59-60.

20. Jende, G., Steiner, U., and Dehne, H. W. 2001. Microscopical characterization of fungicidal effects on infection structures and cell wall formation of Phytophthora infestans. Pages 83-90 in: Modern Fungicides and Antifungal Compounds III. H. W. Dehne, U. Gisi, K. H. Kuck, P. E. Russell, and H. Lyr, eds. AgroConcept and Verlag, Bonn, Germany.

21. Judelson, H. S. 2009. Sexual reproduction in oomycetes: Biology, diversity, and contributions to fitness. Pages 121-138 in: Oomycete Genetics and Genomics. K. Lamour and S. Kamoun, eds. John Wiley \& Sons, Hoboken, NJ.

22. Keinath, A. P. 2007. Sensitivity of populations of Phytophthora capsici from South Carolina to mefenoxam, dimethomorph, zoxamide, and cymoxanil. Plant Dis. 91:743-748.

23. Ko, W. H. 1978. Heterothallic Phytophthora-evidence for hormonalregulation of sexual reproduction. J. Gen. Mycol. 107:15-18.

24. Kuhn, P. J., Pitt, D., Lee, S. A., Wakley, G., and Sheppard, A. N. 1991. Effects of dimethomorph on the morphology and ultrastructure of Phytophthora. Mycol. Res. 95:333-340.

25. Lamour, K. H., and Hausbeck, M. K. 2000. Mefenoxam insensitivity and the sexual stage of Phytophthora capsici in Michigan cucurbit fields. Phytopathology 90:396-400.

26. Olaya, G., Keinath, A. P., Roberts, P. D., and Tally, A. 2008. Sensitivity of Phytophthora capsici isolates to the carboxylic acid amides fungicides mandipropamid and dimethomorph. (Abstr.) Phytopathology 98:S116.

27. Parra, G., and Ristaino, J. B. 2001. Resistance to mefenoxam and metalaxyl among field isolates of Phytophthora capsici causing Phytophthora blight of bell pepper. Plant Dis. 85:1069-1075.

28. Qinxiao, M., Xiaolan, C., Yang, B., Xiaohong, L., Jianjun, H., and Xili, L. 2008. Study on the resistance risk and resistance inheritance of Phytophthora capsici to flumorph. (Abstr.) Phytopathology 98:S128.

29. Reuveni, M. 2003. Activity of the new fungicide benthiavalicarb against Plasmopara viticola and its efficacy in controlling downy mildew in grapevines. Eur. J. Plant Pathol. 109:243-251.

30. Rubin, A., Gotlieb, D., Gisi, U., and Cohen, Y. 2008. Mutagenesis of Phytophthora infestans for resistance against carboxylic acid amide and phenylamide fungicides. Plant Dis. 92:675-683.
31. Sacristan, S., and Garcia-Arenal, F. 2008. The evolution of virulence and pathogenicity in plant pathogen populations. Mol. Plant Pathol. 9:369384.

32. Silvar, C., Merino, F., and Diaz, J. 2006. Diversity of Phytophthora capsici in northwest Spain: analysis of virulence, metalaxyl response, and molecular characterization. Plant Dis. 90:1135-1142.

33. Stein, J. M., and Kirk, W. W. 2004. The generation and quantification of resistance to dimethomorph in Phytophthora infestans. Plant Dis. 88:930-934.

34. Sun, H. Y., Wang, H. C., Stammler, G., Ma, J. X., and Zhou, M. G. 2010. Baseline sensitivity of populations of Phytophthora capsici from China to three carboxylic acid amide (CAA) fungicides and sequence analysis of cholinephosphotranferases from a CAA-sensitive isolate and CAAresistant laboratory mutants. J. Phytopathol. 158:244-252.

35. Wang, H., Sun, H., Stammler, G., Ma, J., and Zhou, M. 2010. Generation and characterization of isolates of Peronophythora litchii resistant to carboxylic acid amide fungicides. Phytopathology 100:522-527.

36. Wang, H. C., Sun, H. Y., Stammler, G., Ma, J. X., and Zhou, M. G. 2009. Baseline and differential sensitivity of Peronophythora litchii (lychee downy blight) to three carboxylic acid amide fungicides. Plant Pathol. 58:571-576.

37. Young, D. H., Spiewak, S. L., and Slawecki, R. A. 2001. Laboratory studies to assess the risk of development of resistance to zoxamide. Pest Manage. Sci. 57:1081-1087.

38. Yuan, S. K., Liu, X. L., Gu, B. G., Dong, J., Jiang, H., and Si, N. G. 2005. Induction and characterization of laboratory mutants of Phytophthora capsici resistant to dimethomorph and flumorph. Agric. Sci. Chin. 4:752759.

39. Yuan, S. K., Liu, X. L., Si, N. G., Dong, J., Gu, B. G., and Jiang, H. 2006. Sensitivity of Phytophthora infestans to flumorph: in vitro determination of baseline sensitivity and the risk of resistance. Plant Pathol. 55:258-263.

40. Zhu, S. S., Liu, P. F., Liu, X. L., Li, J. Q., Yuan, S. K., and Sil, N. G. 2008. Assessing the risk of resistance in Pseudoperonospora cubiensis to the fungicide flumorph in vitro. Pest Manage. Sci. 64:255-261.

41. Zhu, S. S., Liu, X. L., Liu, P. F., Li, Y., Li, J. Q., Wang, H. M., Yuan, S. K., and Si, N. G. 2007. Flumorph is a novel fungicide that disrupts microfilament organization in Phytophthora melonis. Phytopathology 97:643-649

42. Zhu, S. S., Liu, X. L., Wang, Y., Wu, X. H., Liu, P. F., Li, J. Q., Yuan, S. K., and Si, N. G. 2007. Resistance of Pseudoperonospora cubensis to flumorph on cucumber in plastic houses. Plant Pathol. 56:967-975.

43. Ziogas, B. N., Markoglou, A. N., Theodosiou, D. I., Anagnostou, A., and Boutopoulou, S. 2006. A high multi-drug resistance to chemically unrelated oomycete fungicides in Phytophthora infestans. Eur. J. Plant Pathol. 115:283-292. 